\title{
Regional pulmonary blood flow in mitral disease studied by xenon radiospirometry
}

\author{
L. Heslet Andersen, J. K. Johansen, and N. Hyldebrandt \\ with the technical assistance of Mrs. K. M. Damm \\ From the Department of Clinical Physiology, Odense University Hospital, DK-5000 Odense, Denmark
}

Regional lung perfusion was measured in the sitting position by 4 external detectors after intravenous injection of ${ }^{133} \mathrm{Xe}$ in 24 patients with mitral valve disease and in 8 people with no cardiopulmonary disease acting as normal controls. Right- and left-sided heart catheterization was carried out on the patients on the following day. Mitral valve stenosis was found in 9, mitral valve regurgitation in 8 , and both stenosis and regurgitation in the remaining 7.

Regional lung perfusion in the normal people fell linearly.from the basal to the apical sections of the lungs. The perfusion distribution in patients with mitral valve disease and a pulmonary capillary vein (PCV) pressure lower than $15 \mathrm{mmHg}(2.0 \mathrm{kPa})$ did not differ significantly from that of the controls. A redistribution of the regicnal perfusion, with an increase in the apical perfusion and a fall in the basal perfusion of the lungs, was seen in patients with a raised PCV pressure. The hyperperfusion of the apical lung sections correlated with the mean pressure in the pulmonary artery $(r=+0.795, P<0.001)$, while the basal hypoperfusion correlated with the $P C V$ pressure $(r=+0.842, P<0.001)$. The $P C V$ pressure can be predicted with an exactitude of $\pm 7 \mathrm{mmHg}(0.9 \mathrm{kPa})(95 \%$ confidence limits). Neither the cardiac index nor the pulmonary vascular resistance correlated with the changes in perfusion.

Xenon radiospirometry is a rapid and reliable method for evaluating $P C V$ pressure before or after operation in patients with mitral valve disease.

In normal people gravity causes a basal hyperperfusion of the lungs, so that the pulmonary blood flow is greater at the bottom than at the top. Other factors influence the pulmonary blood flow (Jordan, 1965). Basal vascular resistance, measured in the sitting position, decreases when oxygen is breathed (Dawson, Kaneko, and McGregor, 1965) and perivascular oedema (Kazemi et al., 1970) and organic vascular disease can also affect the pulmonary vessels (Olsen, 1966). These factors change the pattern of lung perfusion in patients with mitral valve disease (MVD) (Ball et al., 1962) and may completely invert it.

These perfusion distribution patterns have been studied by means of radioactive gases such as ${ }^{15} \mathrm{O}_{2},{ }^{15} \mathrm{CO}_{2}$ (Dollery and West, 1960), and ${ }^{133} \mathrm{Xe}$ (Ball et al., 1962; Jebavy et al., 1970), and by scanning after the injection of radioactive-labelled albumin aggregate (Friedman and Braunwald, 1966; Giuntini et al., 1974). With ${ }^{133} \mathrm{Xe}$ measure-

Received 17 September 1975. ments of regional blood flow can be repeated and expressed in terms of alveolar perfusion. The technique has therefore been used for studying the perfusion distribution in patients with mitral valve disease, and from this, with the patient in the sitting position, a picture of the pressure in the pulmonary circulation may be obtained.

\section{Patients and methods}

Twenty-four patients with mitral valve disease were studied. By means of right and left heart catheterization the cardiac output was measured by the method of Fick and also a left ventriculogram taken. Nine of the patients had mitral stenosis, 8 had mitral valve insufficiency, while the remaining 7 had both stenosis and regurgitation. The cardiac catheterization data are shown in the Table.

The patients were subjected to regional radiospirometry the day before heart catheterization. ${ }^{133} \mathrm{Xe}$ dissolved in isotonic saline was injected into a cubital vein of the left arm and the radioactivity in the right lung was measured by 4 scintillation detectors placed posteriorly 
TABLE Clinical, cardiac catheterization, and lung perfusion data in 24 patients with mitral valve disease

\begin{tabular}{|c|c|c|c|c|c|c|c|c|c|c|c|}
\hline \multirow{2}{*}{\multicolumn{2}{|c|}{$\begin{array}{l}\text { Case Age } \\
\text { No. (yr) }\end{array}$}} & \multirow[t]{2}{*}{ Sex } & \multirow{2}{*}{$\begin{array}{l}\text { PCV pressure } \\
\text { (mmHg) }\end{array}$} & \multirow{2}{*}{$\begin{array}{l}\text { Mean } A P \\
(m m H g)\end{array}$} & \multirow{2}{*}{$\begin{array}{l}P V R \\
\left(\text { dyn s} \mathrm{s}^{-1} \mathrm{~cm}^{-5}\right)\end{array}$} & \multirow{2}{*}{$\begin{array}{l}\text { Cardiac index } \\
\left(l \min ^{-1} m^{-2}\right)\end{array}$} & \multicolumn{4}{|c|}{ Perfusion index (flow/alveolus) * } & \multirow[t]{2}{*}{ Diagnosis } \\
\hline & & & & & & & 1 & 2 & 3 & 4 & \\
\hline 1 & 45 & $\mathbf{M}$ & 3 & 15 & 196 & $2 \cdot 70$ & 0.546 & 0.676 & 1.005 & $1 \cdot 330$ & $\mathbf{R}$ \\
\hline 2 & 58 & $\mathrm{~F}$ & 5 & 16 & 125 & $2 \cdot 10$ & 0.433 & 0.710 & $1 \cdot 150$ & $1 \cdot 455$ & $\mathbf{R}$ \\
\hline 3 & 47 & F & 6 & 15 & 176 & $2 \cdot 70$ & 0.554 & 0.794 & 1.089 & $1 \cdot 284$ & $\mathbf{R}$ \\
\hline 4 & 58 & $\mathbf{M}$ & 8 & 16 & 130 & $2 \cdot 20$ & 0.622 & 0.750 & 1.028 & 1.269 & $\mathbf{R}$ \\
\hline 5 & 64 & F & 9 & 16 & 82 & $4 \cdot 34$ & 0.492 & 0.759 & 1.061 & 1.478 & $\mathbf{R}$ \\
\hline 6 & 56 & $\mathbf{F}$ & 12 & 16 & 84 & $2 \cdot 10^{\circ}$ & 0.776 & 0.930 & 1.083 & $1 \cdot 118$ & $\mathbf{S}$ \\
\hline 7 & 37 & $\mathbf{F}$ & 14 & 20 & 40 & $4 \cdot 70$ & 0.714 & 0.867 & $1 \cdot 204$ & 1.073 & $\mathbf{R}$ \\
\hline 8 & 53 & $\mathbf{F}$ & 14 & 20 & 160 & 1.80 & 0.782 & 0.937 & $1 \cdot 109$ & 1.033 & $S+R$ \\
\hline 9 & 37 & $\mathbf{F}$ & 14 & 21 & 73 & $5 \cdot 10$ & 0.977 & 1.057 & 1.015 & 0.947 & $\mathbf{R}$ \\
\hline 10 & 59 & $\mathbf{F}$ & 16 & 22 & 55 & 1.60 & 0.761 & 1.000 & 1.091 & 1.011 & $\mathbf{S}$ \\
\hline 11 & 60 & $\mathbf{F}$ & 16 & 17 & 142 & 1.60 & 0.960 & 1.035 & 1.078 & 0.920 & $\mathrm{~S}$ \\
\hline 12 & 49 & F & 17 & 25 & 71 & $2 \cdot 70$ & 0.676 & 0.978 & 1.050 & 1.084 & $S$ \\
\hline 13 & 40 & $\mathbf{M}$ & 17 & 27 & 144 & $3 \cdot 40$ & 0.825 & $1 \cdot 113$ & $1 \cdot 137$ & 0.842 & $S+R$ \\
\hline 14 & 38 & F & 17 & 34 & 384 & $2 \cdot 10$ & 0.906 & 1.062 & 1.037 & 0.899 & $S+R$ \\
\hline 15 & 48 & $\mathbf{F}$ & 20 & 24 & 35 & 1.40 & 0.863 & 0.964 & $1 \cdot 112$ & 0.995 & $S+R$ \\
\hline 16 & 62 & $\mathbf{M}$ & 20 & 32 & 180 & $2 \cdot 70$ & 0.949 & 1.010 & 0.929 & 1.072 & $\mathbf{R}$ \\
\hline 17 & 45 & F & 21 & 30 & 136 & $2 \cdot 80$ & 0.907 & 1.022 & 0.984 & 1.021 & $S+R$ \\
\hline 18 & 61 & $\mathbf{F}$ & 22 & 30 & 108 & 2.60 & $1 \cdot 266$ & 1.080 & 0.929 & 0.771 & $S$ \\
\hline 19 & 51 & $\mathbf{F}$ & 22 & 29 & 267 & $1 \cdot 30$ & $1 \cdot 181$ & 1.053 & 1.093 & 0.737 & $S$ \\
\hline 20 & 67 & M & 24 & 30 & 138 & 1.98 & 1.062 & 0.957 & $1^{1094}$ & 0.917 & $S+R$ \\
\hline 21 & 61 & $\mathrm{~F}$ & 25 & 32 & 175 & $2 \cdot 10$ & $1 \cdot 127$ & $1 \cdot 353$ & 0.909 & 0.855 & S \\
\hline 22 & 36 & F & 25 & 40 & 260 & $2 \cdot 80$ & 1.291 & $1 \cdot 318$ & 0.996 & 0.625 & $S$ \\
\hline 23 & 46 & F & 26 & 32 & 160 & 1.90 & 0.909 & 1.059 & 1.083 & 0.901 & $\mathbf{S}$ \\
\hline 24 & 62 & $\mathbf{F}$ & 26 & 32 & 88 & 3.00 & 1.071 & $1 \cdot 149$ & 1.026 & 0.760 & $\mathbf{S}$ \\
\hline \multicolumn{3}{|c|}{$\begin{array}{l}\text { Mean } 51.7 \\
\pm S D \pm 9.7\end{array}$} & $\begin{array}{r}16.6 \\
\pm 6.9\end{array}$ & $\begin{array}{r}24 \cdot 6 \\
\pm 7 \cdot 4\end{array}$ & $\begin{array}{r}142 \\
\pm 80\end{array}$ & $\begin{array}{c}2.57 \\
\pm 0.99\end{array}$ & $\begin{array}{c}0.860 \\
\pm 0.237\end{array}$ & $\begin{array}{c}0.985 \\
\pm 0.169\end{array}$ & $\begin{array}{c}1.054 \\
\pm 0.072\end{array}$ & $\begin{array}{c}1.016 \\
\pm 0.221\end{array}$ & \\
\hline
\end{tabular}

*Numbers refer to detectors (see Fig. 1).

$\mathrm{PCV}=$ pulmonary capillary venous pressure. $\mathrm{AP}=$ aortic pressure. $\mathrm{PVR}=$ pulmonary vascular resistance.

$\mathbf{S}=$ mitral stenosis. $\mathbf{R}=$ mitral regurgitation.

Conversion from Traditional Units to SI Units: $1 \mathrm{mmHg} \approx 0.133 \mathrm{kPa}$.

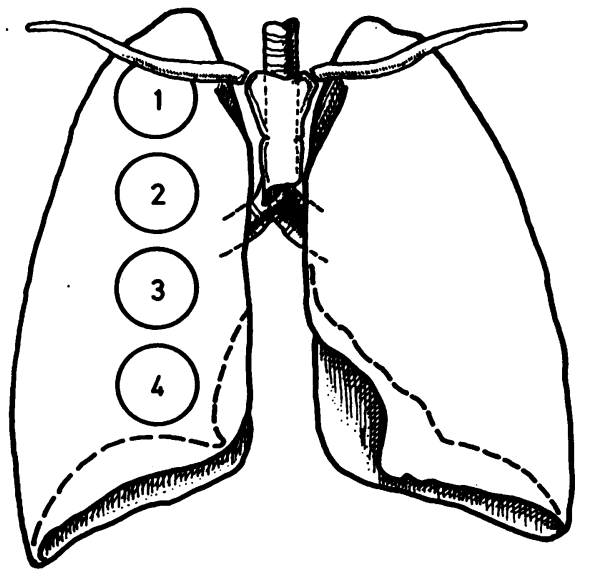

FIG. 1 Positioning of external scintillation detectors vertically over posterior surface of right lung with $18 \mathrm{~cm}$ between centres of upper and lower detector. Internal diameter of each collimator $=4 \mathrm{~cm}$. vertically above each other (Fig. 1). The upper edge of the apical detector corresponded to a line between the superior margin of the right clavicle and the upper margin of the scapula during maximum inspiration (total lung capacity (TLC)). Perfusion measurements were carried out at TLC, where the difference in perfusion between the top and bottom of the lungs is most pronounced (Anthonisen and Milic-Emili, 1966; Hughes et al., 1968; Lilja, 1972). The detectors had a crystal diameter of $5 \mathrm{~cm}$ and a $10-\mathrm{cm}$ long cylindrical collimator. The distance between the centre of the apical and basal detectors was $18 \mathrm{~cm}$ in all the investigations. Each detector was connected to a ratemeter with a time constant of 2 seconds and a discrimination level of $81 \mathrm{KeV}$ (Meditronic). The output of the ratemeter was registered on a 4-channel linear writer with a paper speed of $50 \mathrm{~mm} / \mathrm{s}$.

After an injection of $0.7 \mathrm{mCi}{ }^{183} \mathrm{Xe}$ the patient inspired to TLC and the breath was then held with the glottis open, in order to eliminate activity from the extrapulmonary circulation (right heart and pulmonary arteries): until the output of the ratemeter reached plateau levels (Fig. 2).

The procedure was repeated three times and the mean 


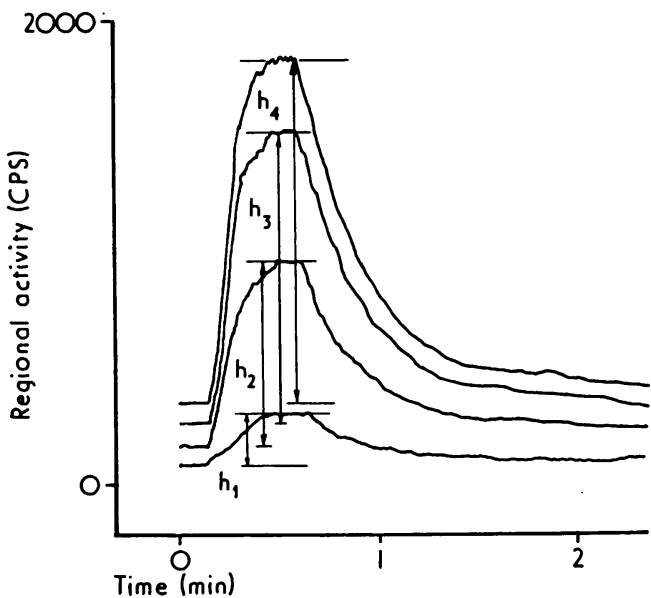

FIG. 2 Regional ratemeter readings of pulmonary blood flow from 4 detectors in a subject without cardiopulmonary disease recorded at maximum inspiration (TLC). Heights of perfusion $h_{1}, h_{2}, h_{3}$, and $h_{4}$ correspond to detectors 1, 2, 3, and 4 in Fig. 1.

of the three readings used for the calculations. After this the patient breathed into a closed system consisting of a 5-litre rubber bag full of oxygen connected to a $\mathrm{CO}_{2}$ absorber. After a stable rebreathing level had been reached the patient inspired again to TLC and continued to do so until the ratemeter output was constant (Fig. 3). At least three measurements were made during inspiration to TLC and the mean regional rebreathing height (Fig. 3) was used for the calculations.

Eight men volunteers, whose mean $( \pm S D)$ age was

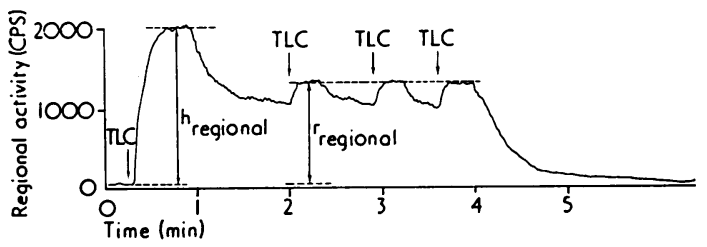

FI G. 3 Regional ratemeter readings of ${ }^{133} \mathrm{Xe}$ activity on rebreathing into closed system with $\mathrm{CO}_{2}$ absorber. $T L C=$ plateaus on three inspirations to TLC. ${ }^{r}$ regional=expression of amount of alveolar air within field of individual detector.

$21 \cdot 2 \pm 2 \cdot 0$ who had no signs of heart or pulmonary disease and whose lung function was normal were subjected to regional radiospirometry by the same technique as described above. The intra-individual coefficient of variation was within 5 per cent.

\section{Calculations}

About 95 per cent of the radioactivity of intravenously injected ${ }^{133} \mathrm{Xe}$ diffuses to the alveolar air during the first passage through the pulmonary circulation (West, 1964). Since ${ }^{188} \mathrm{Xe}$ is uniformly mixed in the right ventricle the amount supplied to each alveolus is proportional to the alveolar blood flow. The height of perfusion ' $h$ ' (Fig. 2) is, therefore, proportional to the regional blood flow. Further, the maximum radioactivity registered during breath holding is proportional to the amount of lung tissue within the field covered by the detector and is dependent on the sensitivity of the detector as well as the dose of ${ }^{133} \mathrm{Xe}$ injected. If the perfusion height registered by each detector is expressed as a percentage of the sum of the four perfusion heights then dosage independence is obtained, as follows:

$$
\mathbf{h}_{\mathbf{n}} \%=\mathbf{h}_{\mathrm{n}} \times 100 /\left(\mathbf{h}_{\mathbf{1}}+\mathbf{h}_{\mathbf{2}}+\mathbf{h}_{\mathbf{3}}+\mathbf{h}_{\mathbf{4}}\right)
$$

where $n=1,2,3$, or 4 , corresponding to the numbering of the detectors in Fig. 1. If the registered activity of each detector after rebreathing and inspiration to TLC (Fig. 3) is expressed as a percentage of the total rebreathing activity then a dosage independent expression of the amount of lung tissue within the field of each detector is obtained as follows:

$$
r_{n} \%=r_{n} \times 100 /\left(r_{1}+r_{2}+r_{3}+r_{4}\right)
$$

where $n=1,2,3$, or 4 .

The ratio $\left(\mathbf{P}_{\mathbf{n}}\right)$ of the perfusion height in per cent $\left(\mathrm{h}_{\mathrm{n}} \%\right)$ and the rebreathing height in per cent $\left(\mathbf{r}_{\mathrm{n}} \%\right)$ $\left(\mathrm{h}_{\mathrm{n}} \% / \mathbf{r}_{\mathrm{n}} \%=\mathrm{P}_{\mathrm{n}}\right)$ is therefore dependent only on the regional perfusion. This ratio $P_{n}$ is termed the perfusion index. Since the size of the alveoli of the apex and base of the lung is the same at maximum inspiration (TLC) (Milic-Emili et al., 1966) $\mathbf{r}_{n}$ per cent is proportional to the number of alveoli, and therefore the perfusion index can be given as flow per alveolus. With increasing perfusion of the apical region the ratio $\mathbf{P}_{1} / \mathbf{P}_{3}$ will increase and is thus an expression of apical hyperperfusion. Similarly, the expression $\mathbf{P}_{1}+\mathbf{P}_{2}+\mathbf{P}_{3} / \mathbf{P}_{4}$ will increase with decreasing basal perfusion and will thus be an expression of the basal hypoperfusion. These indices of perfusion were chosen being most suitable for correlation with the haemodynamic measurements.

\section{Results}

The perfusion indices in the patients with mitral valve disease are shown in the Table and Fig. 4.

In the normal subjects the regional perfusion fell linearly from the base to the apex of the lungs (Fig. 4). A mean bottom/top perfusion ratio $\left(P_{4} / P_{1}\right)$ of 2.7 was measured. If the 24 patients with mitral valve disease are separated into three according to their PCV pressure the pattern of regional perfusion is significantly different. Apical blood flow increases with increasing PCV pressure while basal perfusion decreases (Fig. 4).

In the 9 patients with mitral valve disease and normal ( $<15 \mathrm{mmHg}$ ) PCV pressure at rest (group B) the regional perfusion index was not significantly different from that of the normal subjects (group A). The perfusion indices obtained from detector 3 


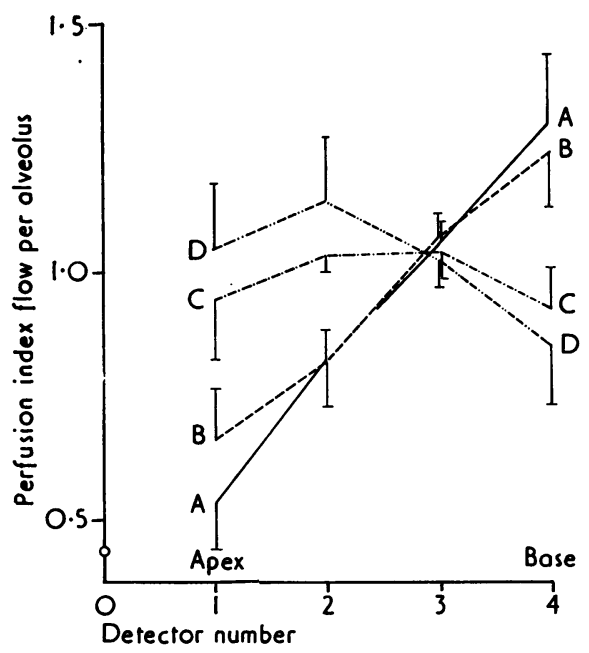

FIG. 4 Regional perfusion indices (flow/alveolus) at TLC in normal subjects $(A)$ and in patients with mitral valve disease $(B, C, D)$. Group $B=9$ patients with mean $A P \quad 17 \cdot 2 \pm 2.4$ (1 SD) $\mathrm{mmHg} \quad(2.3 \pm$ $0.3 \mathrm{kPa})$ and $P C V=9.4 \pm 4.3 \mathrm{mmHg} \quad(1.2 \pm 0.5$ $k P a)$. Group $C=10$ patients with mean $A P 27 \cdot 0 \pm$ $5.1 \mathrm{mmHg} \quad(3.6 \pm 0.7 \mathrm{kPa})$ and $P C V=18 \cdot 8 \pm 2.4$ mmHg $(2.5 \pm 0.3 \mathrm{kPa})$. Group $D=5$ patients with mean $A P \quad 33.2 \pm 3.9 \mathrm{mmHg}(4.4 \pm 0.5 \mathrm{kPa})$ and $P C V=25.2 \pm 0.8 \mathrm{mmHg}(3.3 \pm 0.1 \mathrm{kPa})$. Increased apical perfusion and decreased basal flow occurs with increasing pressures in pulmonary artery and in PCV. Note: all perfusion indices corresponding to detector 3 are independent of measured pressure. Perfusion indices are given $\pm 2 S E M$.

were independent of pressure variations. Apical $\left(\mathbf{P}_{1} / \mathbf{P}_{3}\right)$ and basal perfusion $\left(\mathbf{P}_{1}+\mathbf{P}_{2}+\mathbf{P}_{3} / \mathbf{P}_{4}\right)$ correlated with the pulmonary circulation pressures $(P<0.001)$.

Regression analysis of the relation between PCV pressure and the basal hypoperfusion enables PCV to be predicted with an exactitude of $\pm 7 \mathrm{mmHg}$ $(0.9 \mathrm{kPa})(95 \%$ confidence limits). There was no correlation between cardiac output, cardiac index, or pulmonary vascular resistance and perfusion levels.

\section{Discussion}

In a person in a sitting position lung perfusion is greatest in the basal region because of the higher hydrostatic pressure. We have measured a bottomtop perfusion ratio of 2.7 in normal subjects. That agrees with the results of other radioactive-gas studies (Dawson et al., 1965; Anthonisen and Milic-Emili, 1966; Lilja, 1972) and scannings after the injection of radioactive labelled albumin aggregate (MAA) (Friedman and Braunwald, 1966).

The mean pressure in the pulmonary artery (PA), measured in $\mathrm{cm} \mathrm{H}_{2} \mathrm{O}$, corresponds to the height of the lungs, and for this reason the perfusion pressure is lowest in the apical part. A rise in PA pressure should therefore increase apical perfusion. We confirmed this in our study (Fig. 5). Hypoperfusion of the basal region has been observed with increased PCV pressure (Fig. 6). Such an increase in

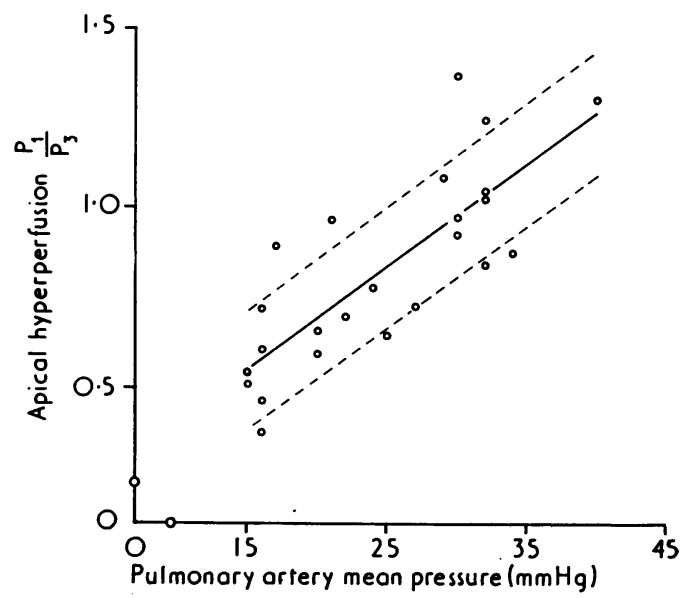

FIG. 5 Apical hyperperfusion. $P_{1} / P_{3}$ related to mean $( \pm S D)$ pressure in pulmonary artery in 24 patients with mitral valve disease. Correlation coefficient : $r=+0.782(P<0.001)$.

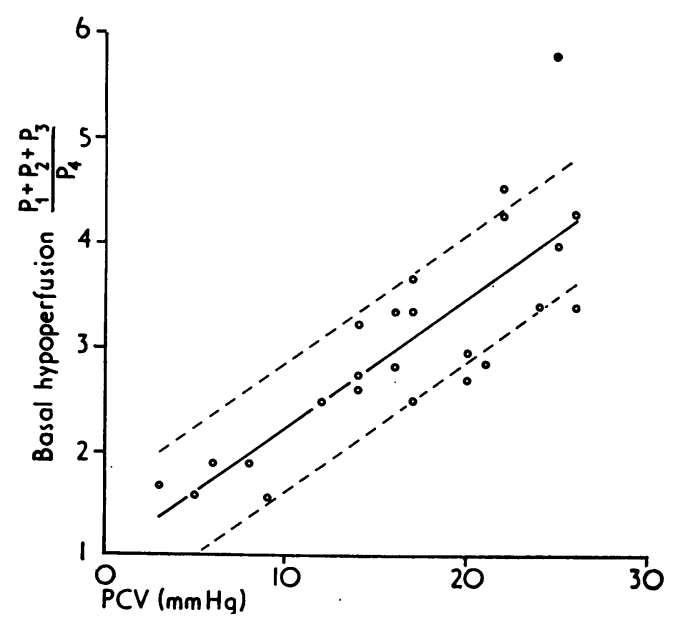

FIG. 6 Basal hypoperfusion. $P_{1}+P_{2}+P_{3} / P_{4}$ related to mean ( $I S D$ ) PCV pressure in 24 patients with mitral valve disease. Correlation coefficient: $r=$ $+0.824(P<0.001)$. 


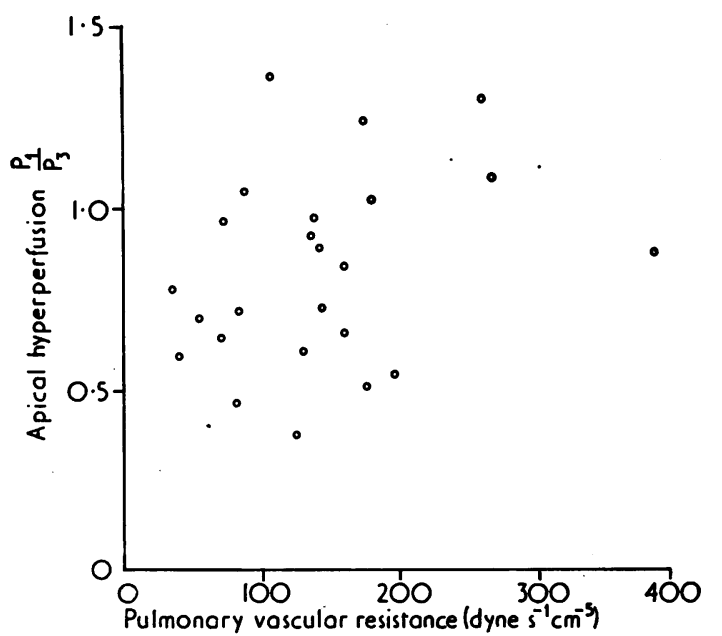

FIG. 7 Apical hyperperfusion. $P_{1} / P_{3}$ related to pulmonary vascular resistance in 24 patients. Correlation coefficient: $r=+0.297$ (not significant).

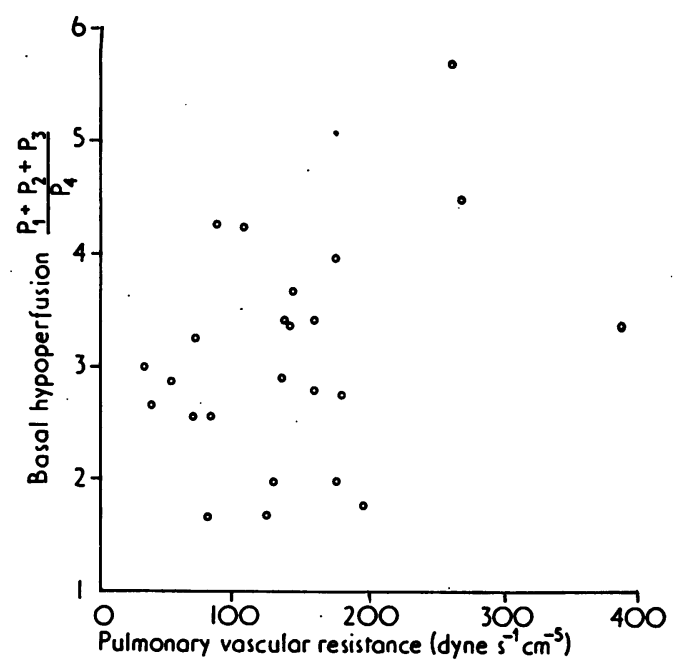

FIG. 8 Basal hypoperfusion. $P_{1}+P_{2}+P_{3} / P_{4}$ related to pulmonary vascular resistance in 24 patients. Correlation coefficient: $r=+0.340$ (not significant).

the basal vascular resistance may be caused by interstitial oedema resulting from a rise in PCV pressure (West, Dollery, and Heard, 1965). Morphological (Olsen, 1966) and functional studies (Steiner, 1958; West et al., 1965) of patients with mitral valve disease (Ball et al., 1962) and of patients with left-sided heart congestion (Kazemi et al.,
1970) have confirmed this.

This basal hypoperfusion is partly reversibleas may be seen in patients with mitral valve disease after oxygen treatment (Dawson et al., 1965) and in the decrease in pulmonary vascular resistance after infusion of acetylcholine into the pulmonary artery (Bateman et al., 1962)-whether or not it is caused by the abolition of vasoconstrictive reflexes as a reaction to a raised PCV pressure or by vasoconstriction resulting from hypoxia (McGregor et al., 1953; Dawson et al., 1965; Bergofsky, Haas, and Porcelli, 1968). Normalization of the pulmonary vascular resistance has not been observed either in these studies or in haemodynamic studies after mitral valve surgery (Zener et al., 1972). This is in agreement with the intimal thickening and perivascular fibrosis of the basal vessels found at necropsy in patients with mitral valve disease (Olsen, 1966).

The reduction in basal perfusion that occurs with age first becomes noticeable after the age of 65 (Holland et al., 1968). This is in agreement with the fact that the perfusion distribution in patients with mitral valve disease with normal PA and PCV pressures does not differ significantly from that of normal subjects, despite the difference in average age (Fig. 4).

Friedman and Braunwald (1966) and Giuntini et al. (1974) found a positive correlation between pulmonary vascular resistance (PVR) and perfusion distribution in the lungs, but Jebavy et al. (1970) and Pain et al. (1972) were unable to do so. This correlation is seen only when radioactive MAA has been used. As the resistance of the pulmonary circulation is low compared with that of the systemic circulation an increase in the basal regional resistance, expressed by a reduction in basal perfusion, would not be expected to influence the total PVR. If the patients are grouped according to the upper normal limit of the basal perfusion (mean value of $\left(P_{1}+P_{2}+P_{3}\right) / P_{4}(+2$ SEM $\left.)=2 \cdot 2\right)$ and with normal PVR $\left(<200\right.$ dyn s$\left.^{-1} \mathrm{~cm}^{-5}\right) 80$ per cent of the patients with normal PVR have reduced basal perfusion and increased apical perfusion (Fig. 7 and 8) without any increase in PVR. The increase in vascular resistance thus results only in a redistribution of the blood to the apical section.

The PVR in patients above the regression line (Fig. 6) is greater than in patients below it $(P<0.02$, $t$ test). Thus an increase in PVR is seen simultaneously with a reduction in basal perfusion but independent of the PCV pressure. There must therefore be factors other than the PCV pressure level that bring about the increased PVR. Such a factor could be the effect on the pulmonary blood vessels of a long-standing disease. 
The lack of correlation between perfusion distribution and PVR when measured by the ${ }^{133} \mathrm{Xe}$ technique compared with the good correlation found when using radioactive MAA could result from physiological differences in the two methods. Tracer MAA is distributed only to the vascular phase while ${ }^{133} \mathrm{Xe}$ is distributed to both the vascular and air phases. Since ventilation and perfusion are complementary (Liljestrand, 1958) this explanation seems improbable. On the other hand, the discrepancy could result from a difference in the patients studied. Friedman and Braunwald (1966) found no correlation between PVR and perfusion distribution with normal PVR values. This is in agreement with our results. Since a correlation has been found between the results with radioactive MAA and ${ }^{133} \mathrm{Xe}$ used on the same patient (Jebavy et al., 1970) probably the lack of correlation between PVR and perfusion distribution is not due to differences in the methods but is a difference in the patients.

With a raised PCV pressure the mean pulmonary artery (PA) pressure will be correspondingly increased. This will occur up to a PCV pressure of $25 \mathrm{mmHg}(3.3 \mathrm{kPa})$, after which the mean PA pressure increases more than the PCV pressure (excessive pulmonary hypertension (Walston et al., 1973)). All our patients had a PCV pressure of $25 \mathrm{mmHg}(3.3 \mathrm{kPa})$ or less, so that the basal perfusion reduction caused by the moderately increased PCV pressure merely resulted in a redistribution of the blood to the apical lung section with an unchanged PVR. When compensatory changes in the blood flow, which occur at a PCV pressure greater that $25 \mathrm{mmHg}(3.3 \mathrm{kPa})$, become so extensive that they involve the apical section an increase in the PVR and a simultaneous normalization of perfusion distribution can first be observed (Friedman and Braunwald, 1966). The regional pulmonary blood flow can be determined partly by radioactivelabelled MAA (Friedman and Braunwald, 1966) and partly by radioactive gases, for example ${ }^{133} \mathrm{Xe}$ (Ball et al., 1962).

When calculating the regional blood flow the regional count rate must be transformed to flow $/ \mathrm{ml}$ lung tissue or flow/alveolus. This is done by a geometrical correction, when using the scanning technique, based on measurement of the lung dimensions on the $x$-ray picture of the thorax (Giuntini et al., 1974). With the ${ }^{133} \mathrm{Xe}$ technique the volume correction is simple, since the rebreathing level is an expression of the amount of lung tissue in the fields of each detector. Perfusion measurements may also be repeated when using ${ }^{133} \mathrm{Xe}$ since the radioactivity expires within minutes. The half life of the tracer most often used, 131IMAA, is three hours (Giuntini et al., 1974), which makes repeated measurements impracticable.

The upper/lower (U/L) perfusion ratio is used in most investigations as an expression of the pulmonary blood flow distribution (Friedman and Braunwald, 1966; Giuntini et al., 1974). U/L will be higher both when the apical perfusion is increased and when the basal perfusion is decreased. We used two distribution ratios, one for apical hyperperfusion $\left(P_{1} / P_{3}\right)$ and another for basal hypoperfusion $\left(\mathbf{P}_{1}+\mathbf{P}_{2}+\mathbf{P}_{3} / \mathbf{P}_{4}\right) . \mathbf{P}_{3}$ constitutes part of the expression for the apical perfusion, as this index has been found to be independent of the measured pressure. $P_{1}+P_{2}+P_{3} / P_{4}$ was used to express the basal hypoperfusion as it gave a better correlation to the PCV pressure $(r=0.821)$ than was the case with $P_{3} / P_{4}(r=0.631)$. This discrimination between the apical and basal perfusion is of little importance so long as the PCV pressure is less than $25 \mathrm{mmHg}$ ( $3.3 \mathrm{kPa}$ ) (passive pulmonary hypertension), but this discrimination would be more physiologically correct in cases where the PA pressure increases more than the PCV pressure.

One of the difficulties of quantitatively measuring the regional perfusion distribution is the determination of the basal lung limits. With increased pulmonary venous pressure the range of maximum perfusion is displaced towards the apical region (Hughes et al., 1969), which makes it even more difficult to determine the basal limits. Our four fixed detectors gave a constant hydrostatic pressure difference between the detectors. The volume correction made from the rebreathing level compensated somewhat for the differences in detector positioning in relation to the base of the lung in calculating the relative perfusion. Thus our correlation coefficients were better than those found when there were varying distances between the detectors (for example, U/L) (Dawson et al., 1965; Jebavy et al., 1970; Pain et al., 1972).

Friedman and Braunwald (1966) found a correlation coefficient of 0.91 for the regression between PCV pressure and U/L in 35 patients, despite the fact that small changes in the cardiac output of patients with mitral valve disease may cause considerable fluctuations in the PCV pressure. Our correlation coefficient, $r=0.821$, was not significantly different from that found by Friedman and Braunwald (1966) $(P>0.05)$. The exactitude with which the PCV pressure can be predicted is $\pm 7 \mathrm{~mm}$ $\mathrm{Hg}(0.9 \mathrm{kPa})(95 \%$ confidence limits), which is comparable with that of $\pm 5 \mathrm{mmHg}(0.7 \mathrm{kPa})(95 \%$ confidence limits) found by Friedman and Braunwald (1966). When there are pathological changes in vessel the walls in the lower zones (Olsen, 1966) the perfusion distribution will not be reliable in predicting changes in the left atrial pressure. 


\section{Conclusion}

The radioactive-xenon method of determining regional pulmonary perfusion in patients with mitral valve disease has been found to be reliable and rapid and may, in contrast to scanning after injection of MAA, be repeated. The volume correction is also simple compared with the scunning technique and the results are immediately available in terms of flow per alveolus. Since it is possible to predict the PCV pressure with an exactitude of $\pm 7 \mathrm{mmHg}(0.9 \mathrm{kPa})$ from the perfusion distribution ( $95 \%$ confidence limits), and since neither extensive intervention nor particular co-operation from the patient are necessary the method can be recommended for the evaluation of patients with suspested mitral valve disease in whom frequent heart catheterization should be avoided-for example, after corrective surgery on the mitral valve.

\section{References}

Ant.zonisen, N. R., and Milic-Emili, J. (1966). Distribution of pulmonary perfusion in erect man. fournal of Applied Physiology, 21, 760.

Ball, W. C., Stewart, P. B., Newsham, L. G. S., and Bates, D. V. (1962). Regional pulmonary function studied with ${ }^{133}$ Xenon. Fournal of Clinical Investigation, 41, 519.

Bateman, M., Davidson, L. A. G., Donald, K. W., and Harris, P. (1962). A comparison of the effect of acetylcholine and $100 \%$ oxygen on the pulmonary circulation in patients with mitral stenosis. Clinical Science, 22, 223.

Bergofsky, E. H., Haas, F., and Porcelli, R. (1968). Determination of the sensitive vascular sites from which hypoxia and hypercapnia elict rises in pulmonary arterial pressure. Federation Proceedings, 27, 1420.

Dawson, A., Kaneko, K., and McGregor, M. (1965). Regional lung function in patients with mitral stenosis studied with ${ }^{133}$ Xenon during air and oxygen breathing. Fournal of Clinical Investigation, 44, 999.

Dollery, C. T., and West, J. B. (1960). Regional uptake of radioactive oxygen, carbon monoxide and carbon dioxide in the lungs of patients with mitral stenosis. Circulation Research, 8, 765.

Friedman, W. F., and Braunwald, E. (1966). Alterations in regional pulmonary blood flow in mitral valve disease studied by radioisotope scanning. Circulation, 34, 363.

Giuntini, C., Mariani, M., Barsotti, A., Fazio, F., and Santolicandro, A. (1974). Factors affecting regional pulmonary blood flow in left heart valvular disease. American Fournal of Medicine, 57, 421.

Holland, J., Milic-Emili, J., Macklem, P. T., and Bates, D. V. (1968). Regional distribution of pulmonary ventilation and perfusion in elderly subjects. Fournal of Clinical Investigation, 47, 81 .
Hughes, J. M. B., Glazier, J. B., Maloney, J. E., and West, J. B. (1968). Effect of lung volume on the distribution of pulmonary blood flow in man. Respiration Physiology, 4, 58.

Hughes, J. M. B., Glazier, J. B., Rosenzweig, D. Y., and West, J. B. (1969). Bactors determining the distribution of pulmonary blood flow in patients with raised pulmonary venous pressure. Clinical Science, 37, 847.

Jebavy, P., Runczik, I., Oppelt, A., Tilsch, J., Stanek, V., and Widimsky, J. (1970). Regional pulmonary function in patients with mitral stenosis in relation to haemodynamic data. British Heart fournal, 32, 330.

Jordan, S. C. (1965). Development of pulmonary hypertension in mitral stenosis. Lancet, 2, 322.

Kazemi, H., Parsons, E. F., Valenca, L. M., and Strieder, D. J. (1970). Distribution of pulmonary blood flow after myocardial ischemia and infarction. Circulation, 41, 1025.

Lilja, B. (1972). Pulmonary blood flow distribution at different lung volumes and body positions. Scandinavian fournal of Clinical and Laboratory Investigation, 29, 351.

Liljestrand, G. (1958). Chemical control of the distribution of the pulmonary blood flow. Acta Physiologica Scandinavica, 44, 216.

McGregor, M., Bothwell, T. H., Zion, M. M., and Bradlow, B. A. (1953). The effects of oxygen breathing on the pulmonary circulation in mitral stenosis. American Heart Fournal, 46, 187.

Milic-Emili, J., Henderson, J. A. M., Dolovich, M. B., Trop, D., and Kaneko, K. (1966). Regional distribution of inspired gas in the lung. Fournal of Applied Physiology, 21, 749.

Olsen, E. G. J. (1966). Perivascular fibrosis in lungs in mitral valve disease. British Fournal of Diseases of the Chest, 60, 129.

Pain, M. C. F., Bucens, D., Cade, J. F., and Sloman, J. G. (1972). Regional lung function in patients with mitral stenosis. Australian and New Zealand Fournal of Medicine, 2, 228.

Steiner, R. E. (1958). Radiological appearances of pulmonary vessels in pulmonary hypertension. British fournal of Radiology, 31, 188.

Walston, A., Peter, R. H., Morris, J. J., Kong, Y., and Behar, V. S. (1973). Clinical implications of pulmonary hypertension in mitral stenosis. American fournal of Cardiology, 32, 650.

West, J. B. (1964). The use of radioactive materials in the study of lung function. Medical Monograph, 1. Radiochemical Centre, Amersham, Bucks.

West, J. B., Dollery, C. T., and Heard, B. E. (1965). Increased pulmonary vascular resistance in the dependent zone of the isolated dog lung caused by perivascular oedema. Circulation Research, 17, 191.

Zener, J. C., Hancock, E. W., Shumway, N. E., and Harrison, D. C. (1972). Regression of extreme pulmonary hypertension after mitral valve surgery. American fournal of Cardiology, 30, 820.

Requests for reprints to Dr. L. H. Andersen, The Department of Clinical Physiology, Odense University Hospital, DK-5000 Odense, Denmark. 